\section{Double layer anisotropy beneath the New Madrid seismic zone and adjacent areas: insights from teleseismic shear wave splitting}

\author{
Moikwathai Dax Moidaki \\ Physics Department, University \\ of Botswana, Gaborone, Botswana
}

\section{Abstract}

A total of 93 well-defined PKS, 54 SKKS, and 126 SKS shear-wave splitting parameters are determined at 25 broadband seismic stations in an approximately 1000 by $1000 \mathrm{~km}^{2}$ area centered at the New Madrid seismic zone (NMSZ) in order to test the existence of two anisotropic layers and to map the direction and strength of mantle fabrics. The individual splitting parameters suggest a significant and systematic spatial and azimuthal variation in the splitting parameters. The azimuthal variations at most stations can be explained as the results of present SW ward asthenospheric flow and NNE trending lithospheric fabrics formed during past orogenic events. In the NMSZ, rift-parallel fast directions (potentially related to a long-rift flow) and rift-orthogonal fast directions from small-scale mantle convection are not observed. In addition, reduction in splitting times as a result of vertical asthenospheric flow is not observed.

\section{Introduction}

Shear waves propagate through an anisotropic mantle as a pair of orthogonally polarized phases that travel at different speeds. ${ }^{1}$ Teleseismic shear-wave splitting of PKS, SKKS and SKS phases (hereinafter are collectively referred to as XKS) provides critical information regarding the structure and dynamics of the earth's upper mantle anisotropy. ${ }^{2-5}$ Individual measurements are generally performed on earthquakes occurring at distances in the range $85^{\circ}$ to $115^{\circ}$. The SKS phase is widely used for shear wave splitting measurements, but for some events, the whole SKS + SKKS wave train was selected. For teleseismic events occurring at distances between $130^{\circ}$ and $140^{\circ}$, PKS and SKKS phases yielded good results. Shear wave splitting measurement is commonly performed on teleseismic Swaves such as SKS, SKKS or PKS phases. These phases are generated by conversion from a $\mathrm{P}$-wave to $\mathrm{S}$-wave at the core-mantle boundary. They are polarized along the radial direction and arrive at the station with a nearly vertical incidence. The presence of energy on the transverse component together with an elliptical particles motion in the horizontal plane indicate that S-waves propagated across an anisotropic medium on their way up to the surface. Splitting measurements are quantified by the delay time $(\delta \mathrm{t})$ between the two shear waves and the orientation $(\Phi)$ of the fast shear wave. The time delay $(\delta \mathrm{t})$ is proportional to the product of the ray path length and the magnitude of anisotropy along the ray path. Laboratory measurements have shown that the a-axis of olivine aligns in the direction of maximum finite extension, or in the direction of mantle flow. ${ }^{6}$ Lattice preferred orientation (LPO) of anisotropic olivine and orthopyroxene crystals in the upper mantle is generally the primary cause of the observed SKS splitting $^{2,7,8}$ and strain-induced LPO is considered to be a valuable indicator of either past or present tectonics. ${ }^{9}$

Shear wave splitting measurements were previously carried out in different tectonic setting ${ }^{1}$ however the debate between strain and anisotropy, amount of deformation caused by past and present lithospheric deformation is ongoing. ${ }^{1,10}$ Seismic anisotropy has been observed in nearly all tectonic settings, such as subduction zones, oceanic basins and continental interiors. ${ }^{11}$ Anisotropy measurements on the continents showed that in compressive regions, anisotropy is caused by vertically coherent deformation of the mantle with fast directions parallel to compressive features. ${ }^{4,12}$ Measurements of splitting parameters on the Baikal rift and East African rift have shown fast directions orthogonal to the extension. ${ }^{13}$ This observation was believed to be caused by abundance of magma filled oriented cracks. Some studies e.g. by Forte et al. ${ }^{14}$ suggest the existence of a vertical asthenospheric flow in the vicinity of the NMSZ induced by the subducting Farallon plate. ${ }^{14}$ Such a flow, if exists, is expected to produce small splitting times beneath the NMSZ.

The main objective of the study is to constrain the spatial variation of anisotropy and quantify the orientation and strength of mantle fabrics beneath the NMSZ. This data set will be used to test the existence of double layer anisotropy in the vicinity of the NMSZ as suggested by Marone and Romanowicz. ${ }^{15} \mathrm{We}$ will also test the plausibility of the model by Forte et al. ${ }^{14}$ which predicts vertical asthenospheric flow beneath the NMSZ. This study will provide important clues on the dependence of fast axis direction on faulting and whether magma filled cracks play a vital role in shear wave splitting in the NMSZ and the surrounding area.

Shear-wave splitting parameters at CCM, MM14, MM15, MM16, MM17 and MM18 were
Correspondence: Moikwathai Dax Moidaki, Physics Department, University of Botswana, P/Bag 00704, Gaborone, Botswana.

E-mail: moidaki@mopipi.ub.bw

Key words: shear wave splitting, New Madrid Seismic Zone, anisotropy, splitting time.

Acknowledgements: data used in the study was obtained from IRIS DMC (http://www.iris.edu/ dms/nodes/dmc/ )

Received for publication: 7 August 2013.

Revision received: 14 January 2014.

Accepted for publication: 15 January 2014.

This work is licensed under a Creative Commons Attribution NonCommercial 3.0 License (CC BYNC 3.0).

\section{(C) Copyright M.D. Moidaki, 2013}

Licensee PAGEPress, Italy

Research in Geophysics 2013; 3:e3

doi:10.4081/rg.2013.e3

previously measured by Fouch et al. ${ }^{12}$ using data from the Missouri to Massachusetts array (MOMA) and spatially uniform station average shear-wave splitting parameters were observed with a fast direction that is parallel to the absolute plate motion (APM) direction. Anisotropy measurements using short-period data from local earthquakes in the NMSZ, recorded by a Portable Array for Numerical Data Acquisition (PANDA), and revealed that the fast polarization directions at most stations are in East-North-East (ENE) direction. ${ }^{16}$ This is consistent with the regional maximum compression stress direction. Such an observation is attributed to the presence of vertical stress aligned cracks, which are considered as the major cause of shear-wave splitting in the Earth's crust. ${ }^{17}$ Crustal anisotropy related to upper crustal fracturing or to lower crustal pervasive fabric may contribute a small amount in splitting times ${ }^{18}$ in the splitting of SKS waves, which is $1 \mathrm{~s}$ on average. ${ }^{1}$ Recent shear wave splitting parameters by Gao et al. ${ }^{19}$ at Arkansas (station MIAR) have shown fast axis directions parallel to the trend of the Ouachita orogeny. Shear wave splitting parameters at stations MIAR, OXF and FVM were also studied by Barruol et al. ${ }^{20}$ The mean splitting parameters were found to be $\Phi=89^{\circ}$ and $\delta t=1.15 \mathrm{~s}$ for MIAR, $\Phi=61^{\circ}$ and $\delta \mathrm{t}=1.55 \mathrm{~s}$ for OXF and $\Phi=42^{\circ}$ and $\delta \mathrm{t}=0.83 \mathrm{~s}$ for FVM.

Shear wave-splitting parameters determined by Marone and Romanowicz ${ }^{15}$ present evidence for the presence of two layers of anisotropy with different fast-axis orientations in the cratonic part of the North American upper mantle. Their study revealed that in the stable interior of North America, at asthenospheric depths of $200-400 \mathrm{~km}$ the fast axis is 
sub-parallel to the absolute plate motion, whereas in the lithosphere, the orientation is significantly more northerly.

\section{Geologic setting of the New Madrid seismic zone and adjacent areas}

The major terrains (Figure 1) in the study area include the extensive Northern Rhyolite terrain (1.69-1.78 Ga), the Mazatzal belt (1.61$1.68 \mathrm{Ga}$ ), and the Granite-Rhyolite terrane (1.48-1.45 Ga). The tectonic blocks are interpreted to have been assembled during two main periods of convergent tectonism: 1.74 to $1.70 \mathrm{Ga}$ (Yavapai orogeny) and 1.65 to $1.63 \mathrm{Ga}$ (Mazatzal orogeny). ${ }^{21}$ The Yavapai-Mazatzal province is made up of supracrustal rocks of the 1.79 to $1.70 \mathrm{Ga}$ Yavapai Supergroup containing mafic to intermediate volcanic rocks, volcaniclastic, and sedimentary rocks. ${ }^{22}$ These are intruded by calc-alkaline batholiths of 1.75 to $1.69 \mathrm{Ga}$ age. The Mazatzal province comprises several blocks with varying ages. ${ }^{21}$ Ages in the Mazatzal block range from $1.74 \mathrm{Ga}$ for a gabbro and 1.70 to $1.69 \mathrm{Ga}$ for a suite of volcanic rocks to a $1.65 \mathrm{Ga}$ age for post-tectonic granite. ${ }^{23}$

The New Madrid rift system is a Precambrian to Middle Cambrian failed rift system, underlying the Illinois basin extending from southern Illinois and western Kentucky southwestward to central Arkansas..$^{24,25}$ The Mississippi embayment is filled with poorly consolidated late Cretaceous and Tertiary shallow marine and fluvial sediments. ${ }^{26}$ The NMSZ within the Mississippi embayment is a southwest-trending aulocogen of late Precambrianearly Paleozoic origin. ${ }^{25}$ Reactivation of Reelfoot rift structures is believed to be responsible for the current seismicity. Geodynamic processes within the rift have had a major influence on basin geometry and subsidence. $^{27}$

\section{Materials and Methods}

\section{Data}

This study uses XKS waveforms recorded by 25 stations, among which 17 are permanent and 8 portable stations. The epicentral distances are $85^{\circ}$ to $140^{\circ}$ for SKS, $120^{\circ}$ to $180^{\circ}$ for PKS and $85^{\circ}$ to $140^{\circ}$ for SKKS. Five of the temporary network stations (MM14-MM18) are part of the MOMA array, deployed from January 1995 to April 1996 with a station spacing of approximately $90 \mathrm{~km} .{ }^{12}$ Station MM15 from the MOMA array did not yield good splitting parameters. Three of the stations (FA07-FA09) are from the Florida to Edmonton (FLED) array. Seismometers of the FLED array were deployed in May 2001 and data collection continued through October 2002. ${ }^{28}$ All analyzed phases have steeply dipping incidence angles and sample the upper mantle almost directly beneath the station, providing very good lateral resolution but poor vertical resolution. As demonstrated below, in spite of limited azimuthal coverage, the combined shear wave splitting results from the PKS, SKKS, and SKS phases are sufficient at most stations to show the existence of double layer anisotropy.

\section{Methods}

The seismograms were band-pass filtered between 0.04 and $0.5 \mathrm{~Hz}$ in order to reduce non-XKS arrivals that would impede the splitting measurement. The XKS time window used to compute the splitting parameters is initially set as $a=15 \mathrm{~s}$ before and $f=35 \mathrm{~s}$ after the predicted phase arrival times based on the IASP91 earth model. About 1127 seismograms were visually checked (328 for PKS, 278 for SKKS and 521 for SKS) to adjust the $a$ and $f$ values. Signals with strong non-XKS arrivals in the XKS window were rejected. We used a method of Silver and $\mathrm{Chan}^{2}$ in estimating the pair of rotation angle and delay time as the most suitable fast polarization angle $\phi$ and split delay time $\delta$ that best minimizes the energy on transverse component with a grid search over possible splitting parameters. Examples of splitting measurements are shown in Figure 2. Silver and Savege ${ }^{29}$ have shown that in the presence of two anisotropic layers, splitting parameters measured under the assumption of a single anisotropic layer will be apparent parameters ( $\Phi \mathrm{a}, \delta$ ta), and will display azimuthal variations. The basis for this double layer is the fact that an incoming near vertical incident phase, which propagates through two homogeneous anisotropic layers, splits twice. Splitting parameters for a double layer model are found by calculating the splitting parameters $(\Phi 1, \delta$ t) for the lower layer and $(\Phi 2$, $\delta t 2)$ for the upper layer.

In this study, the bottom layer was fixed at $\Phi 1=70^{\circ}$ and $\delta \mathrm{t} 1=0.5 \mathrm{~s}$. The direction used for the bottom layer corresponds with the direction of the APM in the study area. Parameters

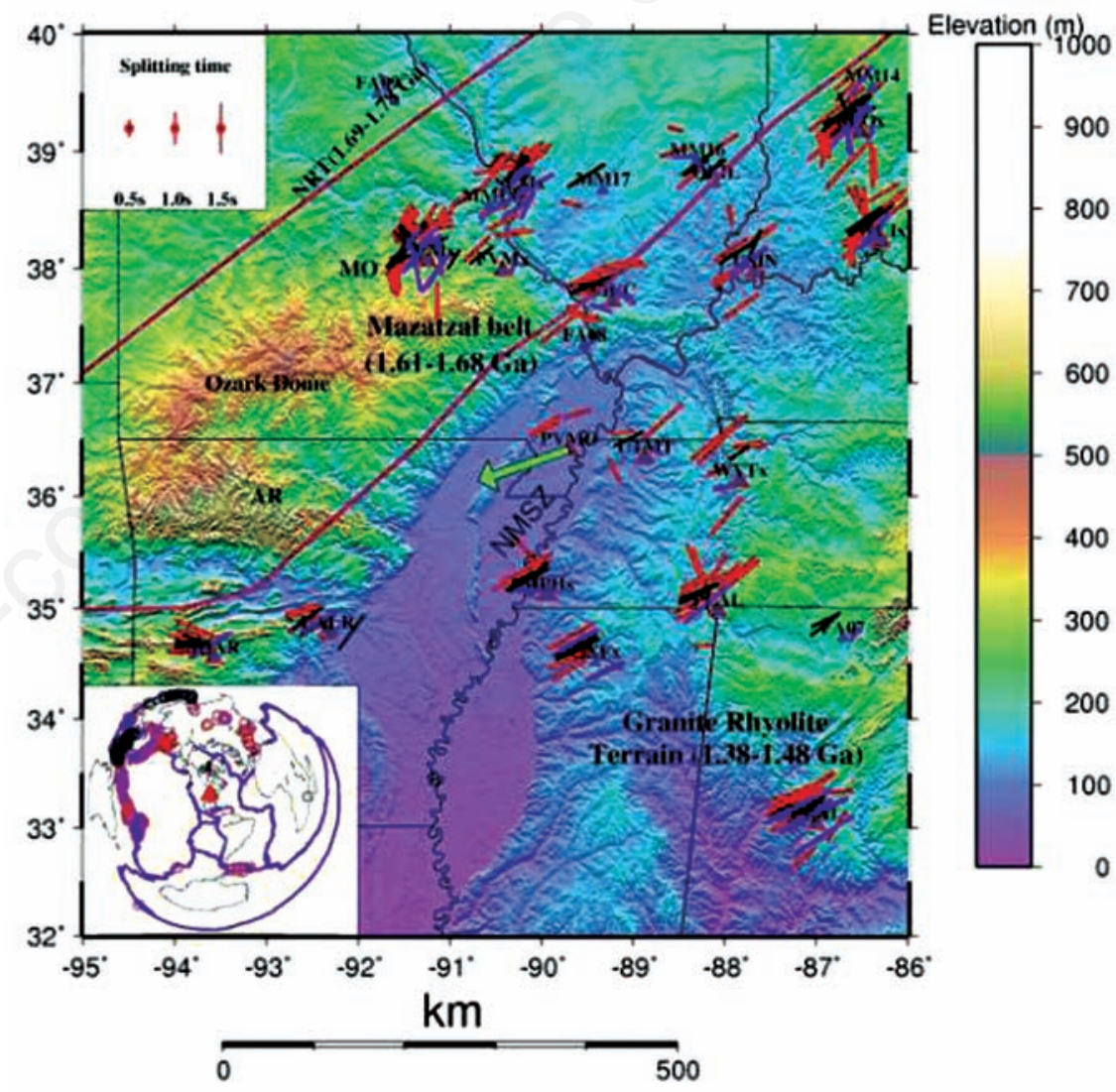

Figure 1. Mercator projection map showing the seismic station locations, major terrains and shear wave splitting results of the New Madrid seismic zone (NMSZ). Red, black and purple represent splitting parameters determined from SKS, PKS and SKKS respectively. Event locations are also shown in the Figure. Azimuthal distribution at stations CCM, BLO, PLAL SIUC, WCI is complex and hence cannot be explained by single layer model. Station MPH UTMT and PVMO within the Mississippi embayment show some degree of alignment with the absolute plate motion (APM). The green arrow at station PVMO represents the direction of plate motion. The red, purple and black circles on the bottom left represent the epicentral distance used for SKS PKS and SKKS respectively. The red triangle represents the seismic station location. NRT, Northern Rhyolite Terraine. 
for the upper layer with the smallest errors were selected to represent the anisotropic parameters for the top layer. The double layer anisotropy parameters are then checked for consistency by comparing the two-layer curve with variation of $\Phi$ against BAZ Modulo $\left(90^{\circ}\right)$. Double layer anisotropy causes the estimated splitting parameter to have a periodicity of $\pi / 2$ as function of back azimuth. ${ }^{29}$ The method of Silver and Savage ${ }^{29}$ was used to perform grid search over the four trial parameters ( $\Phi$ and $\delta \mathrm{t}$ for both upper and lower layers) to determine the optimum two-layer anisotropy model with horizontal fast axes for a dominant signal frequency of $0.2 \mathrm{~Hz}$.

\section{Criteria for selecting quality split- ting parameters}

We objectively ranked the results as quality A (outstanding), B (fair), C (unusable), $\mathrm{N}$ (null), or S (special) by using the method of Liu et $a l .{ }^{30}$ which involves a combination of the following three parameters: i) $R_{o r}$, the signalto-noise ratio on the original radial component that determines the quality of the XKS signal; ii) $R_{o t}$, the signal- to-noise ratio on the original transverse component and is related to the signal strength, magnitude of anisotropy, thickness of the anisotropic layer, and the angle between the fast direction and the arriving azimuth of the SKS ray-path; and iii) $R_{c}$, the signal-to-noise ratio on the corrected transverse component. Its ratio with Rot is a measure of the significance of reduction of the energy on the corrected transverse component. In this study, quality $\mathrm{A}$ and $\mathrm{B}$ results which require $\operatorname{Ror} \geq 10.0$, Rot $\geq 2.0$, and $\operatorname{Rct} / \operatorname{Rot} \leq 0.7$ ) are considered as well-defined measurements and are used in the discussion.

\section{Results}

\section{Azimuthal variation of splitting parameters and the existence of two-layer anisotropy}

Azimuthal dependence in splitting measurements is shown by the plots of $\Phi$ and $\delta \mathrm{t}$ against BAZ (modulo $90^{\circ}$ ) Figures 3 and 4 . The plot of $\Phi$ and $\delta$ as function of BAZ Modulo $90^{\circ}$ for most stations shows a variable or complex distribution of events and polarization direction. The strongest azimuthal dependence is shown by stations CCM, BLO, SIUC, FVM, PLAL, and MPH, OLIL, WCI, USIN, FVM, SLM, MIAR, LRAL, UTMT, WVT, OXF and MPH.

To investigate the existence of a two-layer model, the grid search method ${ }^{29}$ was employed to find the four parameters $(\Phi 1, \delta t 1$ and $\Phi 2$,

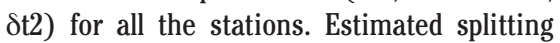
parameters for lower layer beneath each sta- tion except station MIAR indicated a fast polarization direction, which is in good agreement with the APM direction. We then fixed the bottom layer at $\Phi 1=70^{\circ}$ and $\delta t 1=0.5 \mathrm{~s}$ to obtain splitting parameters of the top layer for each station group. The theoretical two-layer curves with parameters in Table 1 are plotted in Figures 3 and 4 . These curves fit fairly well to the variation of $\Phi$ and $\delta$ t as a function of BAZ Modulo $90^{\circ}$ for most stations.

\section{Station: BLOx (39.170, -86.520); Baz= $149.760 \mathrm{deg} .$, Dist $=107.575 \mathrm{deg}$. EQ051631926; Ev-lat= -56.293; Ev-lon= -27.075; Ev-Dep= 94.1km}
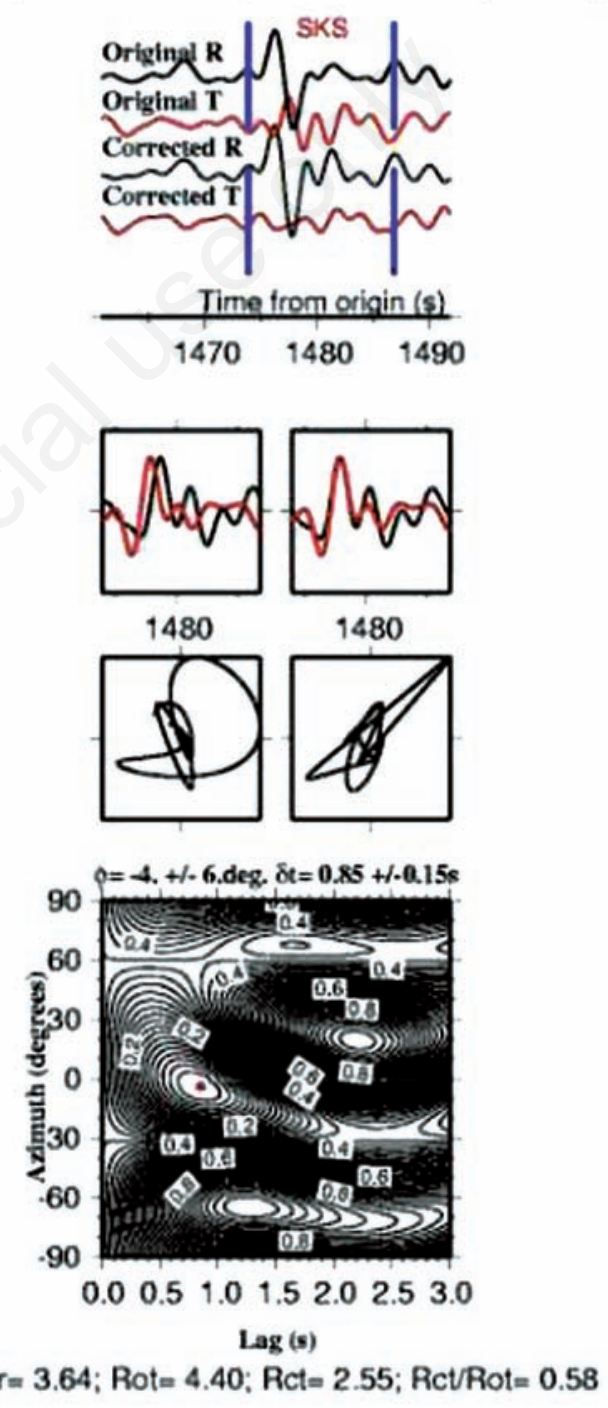

Figure 2. Example of shear wave splitting plots for station BLO. Station: BLOx (39.170, -86.520); The vertical thick blue lines give the time window on which the splitting measurement is made. The four diagrams in the middle represent uncorrected and corrected fast and slow components (black and red lines, respectively) of the split shear waves, with the uncorrected and corrected particle motions in the horizontal plane. The elliptical particle motion becomes rectilinear when the anisotropy is corrected. The lower figure represents the contour plot of energy on the transverse component as a function of the delay time $\delta$ t (seconds) and the polarization angle $\varphi$ (degrees) of the fast split shear wave. 
time as a BAZ Modulo $\left(90^{\circ}\right)$ Figures 4 and 5 . The deviations of apparent splitting angle and time may be caused by scattering effects in the data. Fouch et al. ${ }^{12}$ analyzed data from CCM using three events which were not sufficient to show any complexity in shear wave splitting. The double layer inversion at CCM shows a lower layer with $\Phi 1=49^{\circ}, \delta \mathrm{t} 1=0.8 \mathrm{~s}$ and upper layer with $\Phi 2=21^{\circ}, \delta t 2=0.55 \mathrm{~s}$ and BL0 has lower layer with $\Phi 1=74^{\circ}, \delta \mathrm{t} 1=1.05 \mathrm{~s}$ and upper layer with $\Phi 2=22^{\circ}$, $\delta t 2=0.65$ s. individual splitting measurements at these stations show a counter clockwise splitting pattern. The fast axis directions beneath the two stations are not in the same direction and this sub-parallelism indicates a complex asthenospheric flow beneath the stations.

\section{Spatial grouping of the stations}

The data from this study is divided in eight groups based on the location of each station with respect to nearby stations and azimuthal coverage of events. The parameters for upper layer in a double-layer anisotropy were then calculated with the bottom layer fixed at $\Phi 1=70^{\circ}$ and $\delta$ t 1 at $0.5 \mathrm{~s}$ (Table 1).

Group A stations are on the Mazatzal Belt (1.61-1.68 Ga), a NE trending Precambrian belt. Stations within this group show welldefined measurable splitting parameters on XKS phases. Station CCM was previously studied by Fouch et al. ${ }^{12}$ and observed mean $\Phi=30^{\circ}$ and average $\delta \mathrm{t}=0.9 \mathrm{~s}$ with 3 splitting measurements. Anisotropy measurements at station CCM from 53 SKS, 14 PKS and 18 SKKS show a complex pattern of splitting with fast axis directions showing a counterclockwise rotation of $\Phi$ ranging from $1 \pm 7^{\circ}$ to $179 \pm 14^{\circ}$ with a mean value of $50^{\circ} \pm 7.8^{\circ}$ and $\delta$ ranging from $0.35 \mathrm{~s}$ to $1.9 \mathrm{~s}$ with mean splitting time of $1.0 \pm 0.2 \mathrm{~s}$ (Figures 4 and 5). The observed splitting pattern for this station is a strong indication that anisotropy cannot be estimated by assuming single layer anisotropy. The direction of the APM at the NMSZ is $N 70.9^{\circ} \mathrm{E}^{31}$ on a hotspot reference frame. Our measured fast directions $\delta \Phi$ are sub-parallel to the APM but show close alignment with the trend of
Mazatzal belt. The theoretical two-layer curve for this group is plotted in Figures 4 and 5 with the upper layer thickness at about $117 \mathrm{~km}$ at $4 \%$ anisotropy.

Group B stations (Table 1) are within the Illinois Basin that is underlain by Precambrian basement. Station FVM was previously studied by Barruol et al. ${ }^{20}$ and obtained $\Phi$ of $42^{\circ}$ and $\delta t$ of $0.83 \mathrm{~s}$. In this study, 1 PKS, 1 SKKS and 4 SKS measurements were obtained with $\Phi$ ranging from $13 \pm 7^{\circ}$ to $81 \pm 8^{\circ}$ with a mean $\Phi$ of $55 \pm 9.5^{\circ}$ and $\delta$ ranging from $0.55 \pm 0.12 \mathrm{~s}$ to $1.0 \pm 0.17 \mathrm{~s}$ with a mean of $0.8 \pm 0.2 \mathrm{~s}$. individual splitting measurements are shown in Table 1 and the parameters for the double anistropy are shown in Figures 4 and 5.
Group $C$ stations show a complex splitting pattern that is different from the surrounding stations. FA08 is at the tip of the Mississippi embayment/Reelfoot escarpment but south of station SIUC and has one SKS splitting pair with $\Phi=51 \pm 7^{\circ}$ and $\delta \mathrm{t}=1.45 \pm 0.48 \mathrm{~s}$. Because of the close proximity of FA08 to SIUC, the theoretical curves shown in Figures 4 and 5 were calculated using the combined splitting parameters from these two stations. The anisotropic layer thickness of the upper layer is about 33 $\mathrm{km}$ at $4 \%$ anisotropy

Group $D$ stations show complex splitting pattern and the events have similar azimuthal distribution except MM14, which shows events azimuth from a narrow window. Rotation pat-

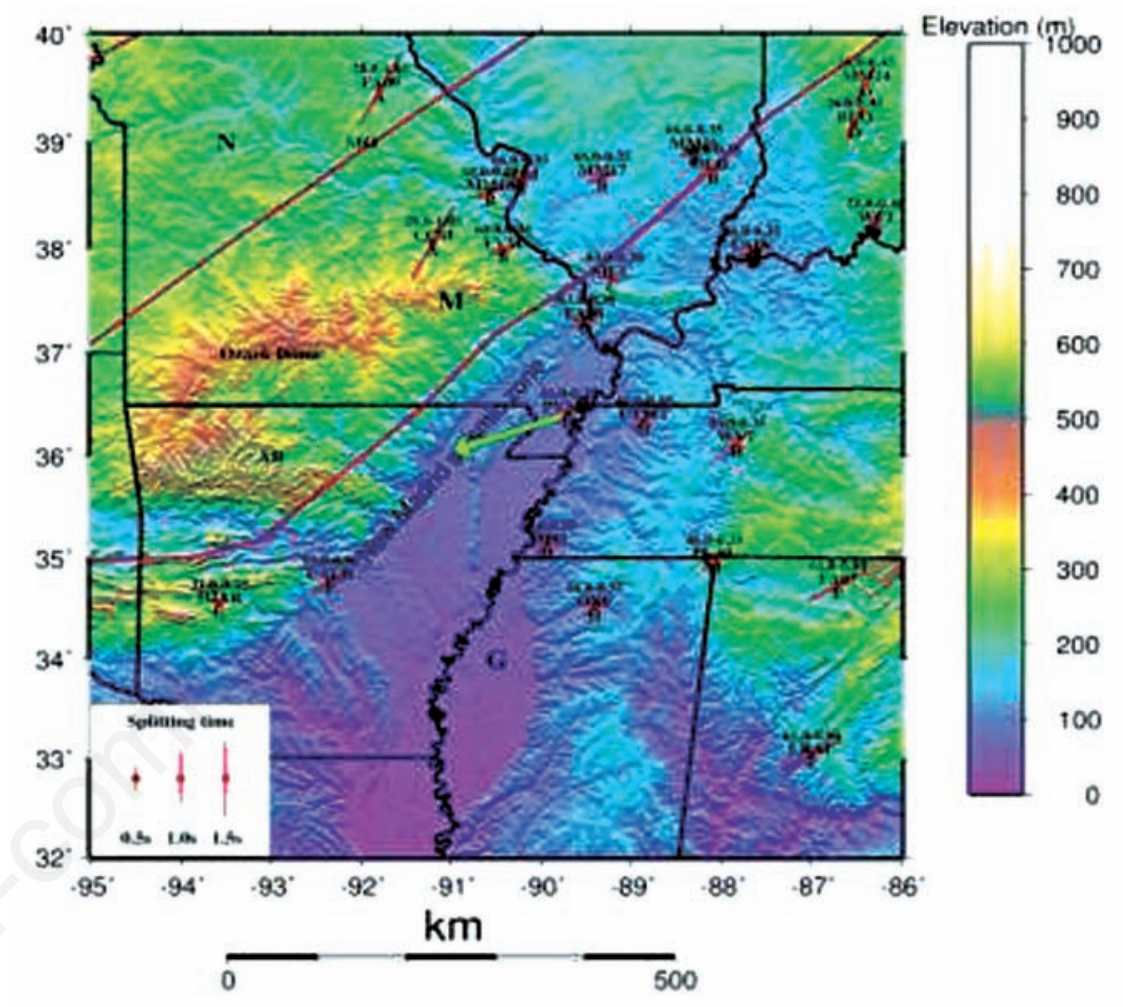

Figure 3. Distribution of fast axis direction for the upper layer with lower layer fixed at Phil=70 deg. and Dt1=0.5 s. The letters below the station names are station groups. G, Granite Rhyolite Terrain; M, Mazatzal Belt; N, Northern Rhyolite Terrain.

Table 1. Station groups and upper layer parameters.

\begin{tabular}{|c|c|c|c|c|c|}
\hline Groups & Station names & $\Phi 1$ (deg.) & $\delta \mathrm{t} 1(\mathrm{~s})$ & Ф2 (deg.) & $\delta \mathrm{t} 2(\mathrm{~s})$ \\
\hline $\mathrm{A}$ & CCM, FA09 & 70 & 0.5 & 28 & 1.05 \\
\hline B & FVM, SLM, MM16, MM17, MM18, OLIL, USIN & 70 & 0.5 & 66 & 0.35 \\
\hline $\mathrm{C}$ & SIUC, FA08 & 70 & 0.5 & -83 & 0.3 \\
\hline D & BLO, WCI, MM14 & 70 & 0.5 & 26 & 0.45 \\
\hline E & LRAL, FA07 & 70 & 0.5 & 61 & 0.8 \\
\hline $\mathrm{F}$ & UALR & 70 & 0.5 & 55 & 0.5 \\
\hline $\mathrm{G}$ & MIAR* & 70 & 0.5 & - & - \\
\hline $\mathrm{H}$ & PVMO, UTMT, WVT, MPH, OXF, PLAL & 70 & 0.5 & 46 & 0.35 \\
\hline
\end{tabular}


tern at station BLO is an indication that the anisotropy complex and cannot be explained by single layer model or simple asthenospheric flow. Individual splitting measurements for station WCI reveal a much more complicated pattern of splitting. Interpretation of splitting parameters from MOMA array suggests single layer anisotropy in this area. ${ }^{12}$ Three SKS measurements from MM14 (mean $\Phi=53^{\circ}$ and mean $\delta \mathrm{t}=0.95 \mathrm{~s}$ for SKS phase); Fouch et al. ${ }^{12}$ show $\Phi$ values ranging from $35 \pm 8^{\circ}$ to $51 \pm 5^{\circ}$ with a mean of $44.3 \pm 5.7$ and $\delta$ values ranging from $0.8 \pm 0.07 \mathrm{~s}$ to $1.2 \pm 0.4 \mathrm{~s}$ with a mean of $1.01 \pm 1.2 \mathrm{~s}$. MM15 did not yield good splitting parameters because of low signal to noise ratio within the expected shear wave splitting window but Fouch et al..$^{12}$ found mean $\Phi$ of $60^{\circ}$ and mean $\delta \mathrm{t}=0.9 \mathrm{~s}$ for SKS phase.

Group E stations are on the Appalachian Orogeny and have consistent splitting pairs trending in the NE direction. LRAL has the largest delay times (Table 2) for all the phases and the splitting pattern is consistent for all the phases. The grid search method for this group resulted to $\Phi 2=61^{\circ}, \delta \mathrm{t} 2=0.8 \mathrm{~s}$ for the top layer with the bottom layer fixed at $\Phi 1=70^{\circ}$, $\delta \mathrm{t} 1=0.5 \mathrm{~s}$. the layer thickness of the upper layer is about $89 \mathrm{~km}$ at $4 \%$ anisotropy.

Group $F$ includes UALR which is approximately $130 \mathrm{~km}$ from MIAR but the average splitting parameters are different from MIAR. The $\Phi$ from 3 PKS, 1 SKKS and 3 SKS phases ranges from $36 \pm 6^{\circ}$ to $73 \pm 16^{\circ}$ with a mean of $46.5 \pm 7.4^{\circ}$ and $\delta$ ranging from $0.9 \pm 0.15 \mathrm{~s}$ to $1.25 \pm 0.2 \mathrm{~s}$ with a mean of $1.05 \pm 0.27 \mathrm{~s}$. With the bottom layer fixed at $\Phi 1=70^{\circ}, \delta \mathrm{t} 1=0.5 \mathrm{~s}$, the top anisotropic layer has $\Phi 2=55^{\circ}, \delta \mathrm{t} 2=0.5$ $\mathrm{s}$ with a thickness of about $55 \mathrm{~km}$ calculated at $4 \%$ anisotropy.

Group G: MIAR. This station is situated on Ouachita orogeny and has fast axis direction in EW direction. MIAR was previously studied by Gripp and Gordon ${ }^{31}$ and showed a mean $\Phi$ of $112 \pm 8^{\circ}$ and splitting time of $0.7 \pm 0.2 \mathrm{~s}$ using the sks phase. The same station was studied by Barruol et al. ${ }^{20}$ and obtained mean $\Phi$ of $89^{\circ}$ and $\delta$ t of $1.15 \mathrm{~s}$ but XKS phases from this study and individual splitting measurements for these stations are shown in Figure 1. The observed $\Phi$ values vary from $59 \pm 7^{\circ}$ to $113 \pm 7^{\circ}$ with a mean of $96.8 \pm 7.8^{\circ}$ and $\delta$ t ranges from $0.65 \pm 0.15 \mathrm{~s}$ to $1.2 \pm 0.25 \mathrm{~s}$ with a mean of $0.99 \pm 0.27 \mathrm{~s}$. The fast axis direction coincides with strike of the Ouachita orogeny. With bottom layer fixed at $\Phi 1=70^{\circ}$ and $\delta$ tl at $0.5 \mathrm{~s}$. The grid search method did not yield a good fit for this station. The grid search method of Savage and Silver ${ }^{32}$ without fixing the bottom layer resulted in the following parameters for the double layer model; $\Phi 1=79^{\circ}, \delta t 1=1.1 \mathrm{~s}$ for the lower layer and $\Phi 2=31^{\circ}, \delta \mathrm{t} 2=0.25 \mathrm{~s}$ for the upper layer. The lower layer coincides with the trend of the Ouachita orogenic belt. Previous studies for this station have indicated that upper mantle anisotropy beneath MIAR could be represented by single layer model. ${ }^{30}$

Group H: stations (Table 1) are in the immediate vicinity of the NMSZ. PVMO is located
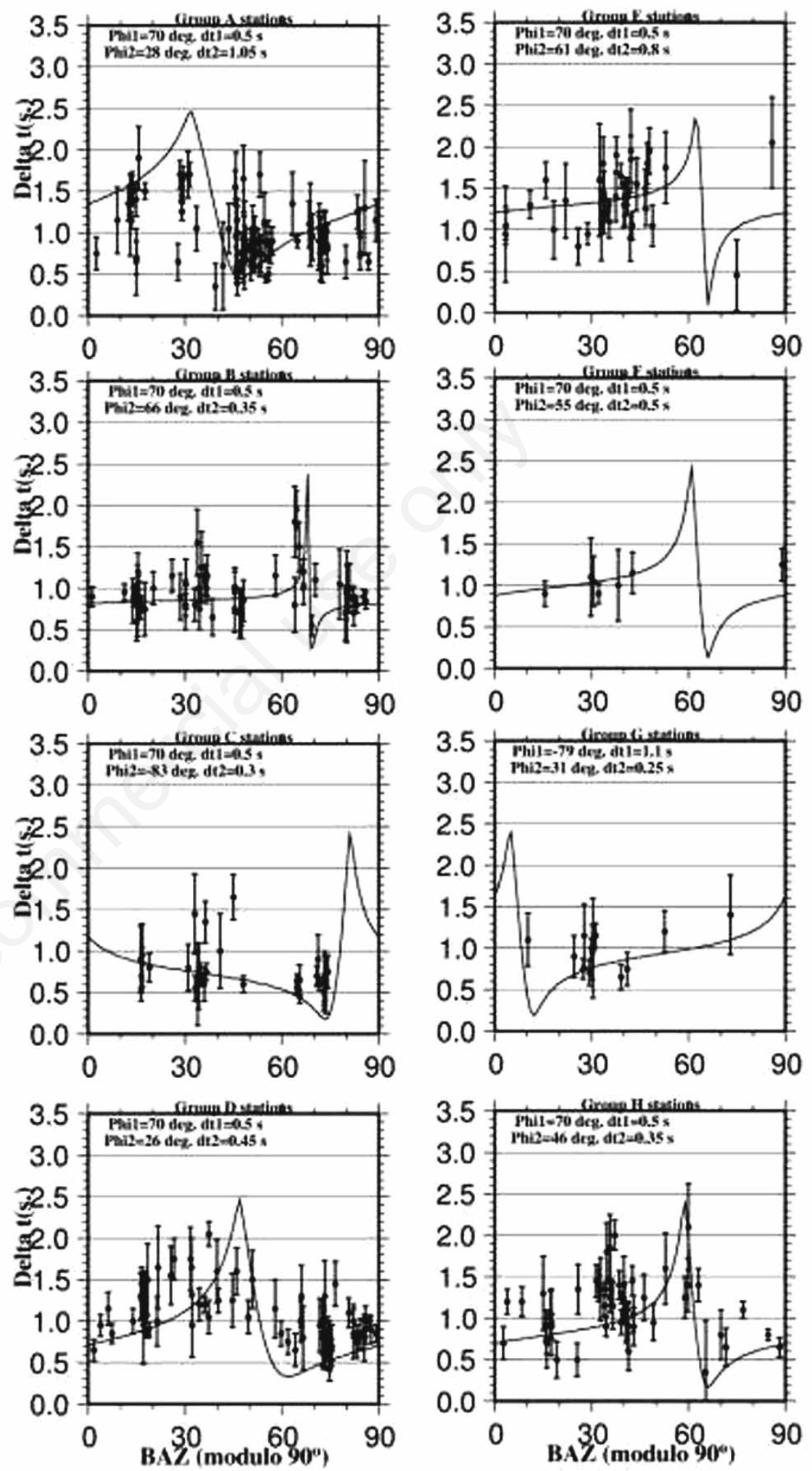

Figure 4. High quality measurements of $\delta \mathrm{t} v s \mathrm{BAZ}\left(\operatorname{modulo} 90^{\circ}\right)$ for the stations in the New Madrid seismic zone (NMSZ) and nearby stations. The double anisotropic was estimated with theoretical two-layer calculated with bottom layer fixed at $\mathrm{Phi}=70 \mathrm{deg}$. and Dt at $0.5 \mathrm{~s}$. 
than expected for crustal anisotropy. The deviations of the apparent splitting parameters from the theoretical curves are likely to be caused by scattering effects in the data and due to using only a single frequency $(0.15 \mathrm{~Hz})$ in calculating the curves. PLAL show a complex splitting pattern with polarization angle $(\Phi)$ ranging from $35 \pm 13^{\circ}$ to $160 \pm 1^{\circ}$ with a mean of $70.3 \pm 6.6^{\circ}$ and the delay times $\delta$ t ranges from $0.5 \pm 0.2 \mathrm{~s}$ to $1.8 \pm 0.4 \mathrm{~s}$ with a mean of $1.15 \pm 0.26$. Previous mean measurements of SKS phase for this station by Fouch et al. ${ }^{12}$ revealed $\Phi$ of $170^{\circ}$ and $\delta t$ of $1.35 \mathrm{~s}$. Their mean $\Phi$ is different from the mean from this study which (from 17 events) is $70.3 \pm 6.6^{\circ}$ and $\delta \mathrm{t}=1.15 \pm 0.26 \mathrm{~s}$. The fast axis direction from this study has a similar trend as APM. The grid search method resulted to $\Phi 2=46^{\circ}, \delta \mathrm{t} 2=0.35 \mathrm{~s}$ for the top layer with the bottom layer fixed at $\Phi 1=70^{\circ}, \delta t 1=0.5 \mathrm{~s}$. The layer thickness of the upper layer is about $39 \mathrm{~km}$ at $4 \%$ anisotropy

\section{Discussion}

\section{Source of anisotropy}

The hypotheses related to the source of anisotropy include i) mantle anisotropy induced by extension due to a LPO of olivine, ii) anisotropy due to an alignment of parallel dikes or melt-filled lenses, iii) fossilized anisotropy in the lithospheric mantle from previous orogenic events, and iv) mantle anisotropy due to shear related flow at the base of the lithosphere or cratonic keel, v) asthenospheric flow in the direction of APM. The above hypothesis are vital because the study area is tectonically complicated and comprises of North American craton, an active rift system (Reelfoot rift), orogenic belts, magmatism, and possible influence from Bermuda hotspot. $^{30}$

\section{Fossilized anisotropy due to exten- sion/compression}

Continental regions exhibit splitting patterns that are closely related to surficial geologic features, suggesting a lithospheric origin related to the fabric that was generated by the most recent significant tectonic event. ${ }^{1,20}$ Splitting measurements in the NMSZ are subparallel to surface geologic features and hence lithospheric anisotropy cannot be invoked as main cause of the observed anisotropy. Shear wave splitting on ocean ridges (e.g., the Red $\mathrm{Sea}^{33}$ ) and on continental rifts (e.g., Baikal rift $^{13}$ show fast splitting directions parallel to the extension direction. In extensional regime, ductile stretching of the mantle lithosphere should produce a lattice preferred orientation of olivine fast axes in the direction of extension. In areas where strain is controlled by dislocation creep, ${ }^{34,35}$ LPO of olivine fast aaxes aligns with the direction of extension. Compressive regimes show fast axis directions that are aligned perpendicular to the direction of compressive forces. In the NMSZ the exten-
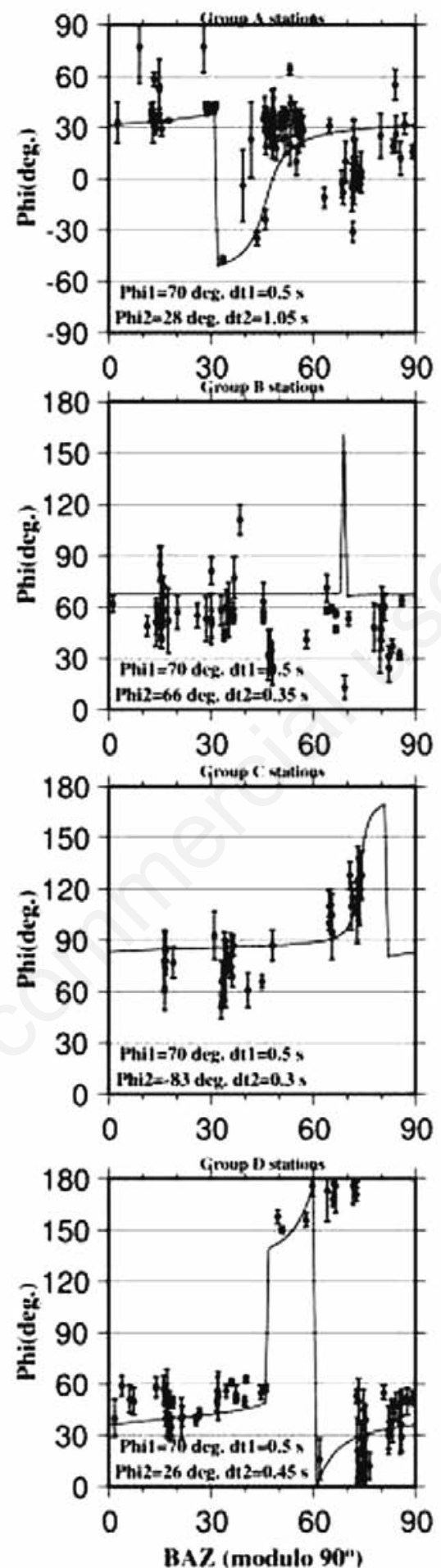

sion direction of the rift is NE. Our results (Figure 3) are sub-parallel to the extension direction, and so extension-driven rift-perpendicular material flow is not likely to be a possible cause of the observed anisotropy.
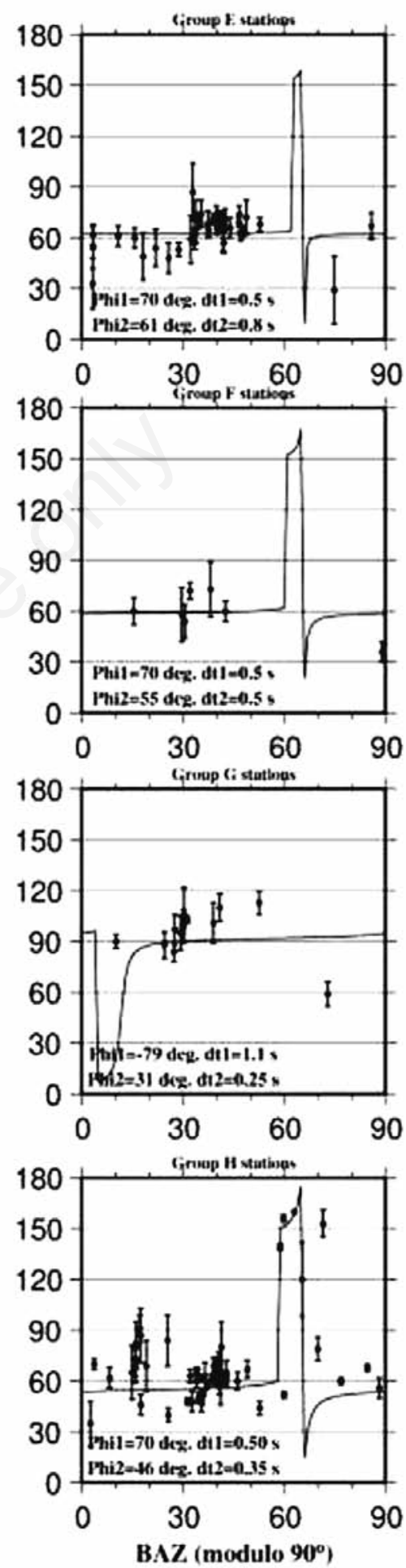

Figure 5. High quality measurements of $\Phi v s$ BAZ (modulo $\left.90^{\circ}\right)$ for the stations in the New Madrid seismic zone (NMSZ) and nearby stations. The stations have been modeled by double anisotropic layers with theoretical two-layer curves plotted. The bottom layer was fixed at $70 \mathrm{deg}$. and $\mathrm{Dt}=0.5 \mathrm{~s}$. 
The splitting measurements on the NMSZ and the surrounding presented above show sub-parallelism of fast axis of polarization with the local structural trend suggesting that old lithospheric structures control the observed splitting parameters to some degree but the splitting time is more than expected for crustal anisotropy. ${ }^{1}$ Parallelism of the fast axis direction with the strike of geological features are observed at most stations in Figure 1 even though stations CCM, BLO, MIAR and WCI show complex splitting patterns. This type of alignment has been observed in areas of active transpression. ${ }^{1,12}$ The average fast directions of the stations within the rift are approximately sub-parallel to trend of the rift (Figure 6). Such parallelism suggests that anisotropy could be related to deep-seated rift structures and rift processes. Fast directions along the trend of the rift could be related to the preferred alignment of magma filled pockets/dykes with a long axis parallel to the maximum compressive direction and a short axis parallel to the minimum compressive (extension) direction.$^{36}$ Rift parallel dikes may form a transverse anisotropy with a rift orthogonal axis of symmetry. The fast direction of the anisotropy would be parallel to the strike of the dikes/rift axis. The crustal contribution is not likely to be significant and typically amounts to 0.04-0.2 s of splitting ${ }^{1,37}$ indicating that the majority of SKS shear wave splitting occurs in the mantle. The effect of crustal anisotropy is not apparent thus, the upper mantle is considered the most likely source of the anisotropy in NMSZ.

Significant anisotropy may also be induced by flow of asthenospheric material between steeply dipping rift border faults. ${ }^{38}$ It is widely observed that the fast polarization of crustal shear waves is parallel to the local strike of cracks or direction of the maximum horizontal compressive stress. ${ }^{39}$ However in the NMSZ we observe subtle correlation between splitting parameters and the trend of the Reelfoot faults. The observed splitting parameters could be olivine LPO anisotropy due to ductile lithospheric compression associated with NE/SW compressive forces at the NMSZ. Zoback and Zoback $^{40}$ indicated that the direction of maximum stress in the central United States is approximately east west compressive, but in the central part of the NMSZ (the area surrounding Kentucky Bend), the stress-direction data indicate a rotation to northeast-southwest compression.

The North American plate has been modified by multiple orogenic events; therefore vertically incoherent anisotropy and inconsistent splitting are expected. The fast axis direction for the North American plate within the NMSZ show an orientation sub-parallel to the major trend of geologic structures exposed at the surface. Increasing pattern of $\delta$ with increasing lithospheric thickness can be explained well by fossilized lithospheric anisotropy. ${ }^{41}$ Plomerova et al. ${ }^{42}$ suggest that sudden changes of splitting parameters relate to distinct tectonic sutures, or to boundaries of suspect terranes which could be associated with fossil structure of the mantle lithosphere. The olivine orientation due to the present-day flow or local circulations in the sub-lithospheric mantle are generally considered to be very small beneath cratons. ${ }^{43}$ Variations in average splitting parameters beneath the South America cratons are explained by local deflections of the sub-lithospheric flow due to lithosphere thickness variations. ${ }^{44}$ Barruol et al. ${ }^{45}$ and Wustefeld ${ }^{46}$ found several arguments supporting frozen lithospheric anisotropy in cratonic areas. Mareschsl and Jaupert ${ }^{47}$ estimate the temperatures at 150 $\mathrm{km}$ depth during the Archean to be $150 \mathrm{~K}$ higher than present, implying the lithosphere remains sufficiently cold and strong to preserve Archean fabrics.

\section{Anisotropy due to absolute plate motion}

Some regions exhibit patterns of seismic anisotropy more closely related to the local direction of APM in the hotspot reference frame $^{8,33}$ suggesting that seismic anisotropy exists primarily in the sub-lithospheric mantle and is generated by fabric resulting from mantle flow. The current APM direction of NMSZ is $\mathrm{N} 70^{\circ} \mathrm{E}^{31}$ Our observed fast azimuths show a

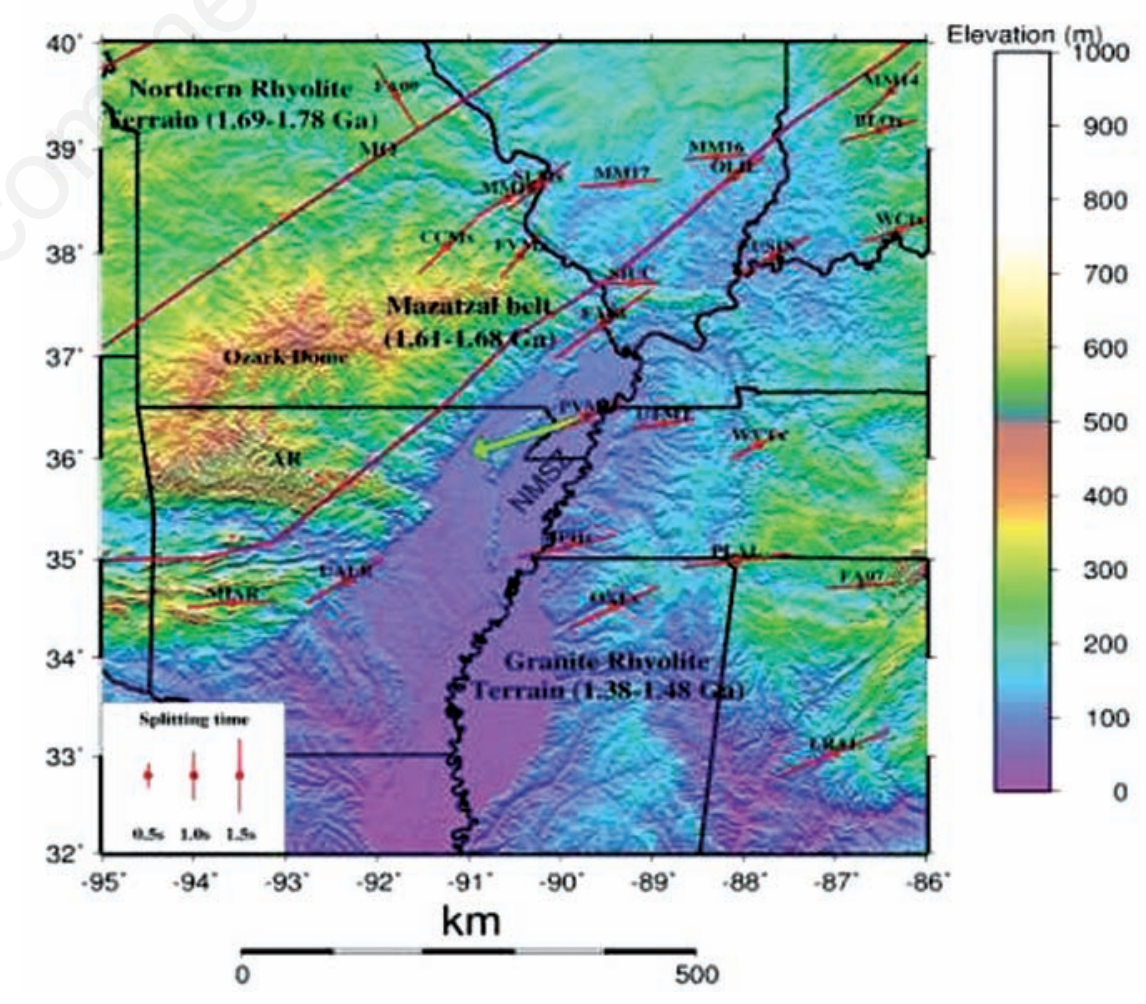

Figure 6. Mercator projection map of mean values of all phases per station. Large mean delay times are observed at LRAL and small mean delay times are found at stations FVM, UTMT, SIUC and PVMO. strong correlation with this $\mathrm{N} 70^{\circ} \mathrm{E}$ APM direction of within the NMSZ. Observed anisotropy results in NMSZ are therefore partly explained by the simple asthenospheric flow hypothesis. Mantle material may flow beneath and around continental keels with complex morphologies, generating a fabric that mimics the keel shape. ${ }^{13}$ Observations of seismic anisotropy have led to the conclusion that the observed anisotropy on continental settings is a combination of both lithospheric and sublithospheric fabric. ${ }^{13,48}$

Fast axis direction at MAIR show large angle between the fast direction from the lower layer and APM direction with the upper layer at $\mathrm{N} 31^{\circ} \mathrm{E}$. The large deviation between the lower layer and APM direction could be caused by asthenospheric flow around the continental root. The most intriguing observation for this station is the parallelism of the trend of surface expressions of Ouachita orogeny with fast axis of the lower later. This suggests that the observed splitting parameters are a contribution from both lithosphere and asthenosphere. Geophysical model by Plomerova et al. ${ }^{42}$ suggest that the strike of orogeny observed on the surface does not necessarily represent regional trend of the orogeny and lithospheric deformation at depth. Studies by Fouch et al. ${ }^{12}$ show NE-SW fast directions on the North American craton that are parallel the APM and are different from the fast directions at MIAR. Station UALR is close to MIAR (Figure 1) but the direc- 
Table 2. Average SKS, PKS and SKKS splitting results for the New Madrid seismic zone.

\begin{tabular}{|c|c|c|c|c|c|c|c|c|c|c|}
\hline \multirow{2}{*}{$\begin{array}{l}\text { Station } \\
\text { name }\end{array}$} & \multicolumn{2}{|c|}{ Coordinates } & \multirow{2}{*}{$\begin{array}{c}\text { Fast } \\
\text { direction } \\
\text { (Deg.) }\end{array}$} & \multirow{2}{*}{$\begin{array}{c}\text { Fast } \\
\text { direction } \\
\text { ( } \Delta \text { degree })\end{array}$} & \multirow{2}{*}{$\begin{array}{l}\text { Splitting } \\
\text { time } \\
\text { (s) }\end{array}$} & \multirow{2}{*}{$\begin{array}{l}\text { Splitting } \\
\text { time } \\
(\Delta s)\end{array}$} & \multirow{2}{*}{$\begin{array}{l}\text { Number } \\
\text { of events }\end{array}$} & \multirow{2}{*}{\multicolumn{2}{|c|}{$\begin{array}{c}\text { Weighted } \\
\text { mean }\end{array}$}} & \multirow[t]{2}{*}{ Phase } \\
\hline & $\begin{array}{l}\text { Latitude } \\
\text { (Deg.) }\end{array}$ & $\begin{array}{l}\text { Longitude } \\
\text { (Deg.) }\end{array}$ & & & & & & & $\Delta s$ & \\
\hline BLO* & 39.17 & -86.52 & 63.53 & 26.13 & 1.04 & 0.26 & 12 & 0.48 & 0.02 & PKS \\
\hline BLO* & 39.17 & -86.52 & 102.51 & 72.38 & 0.88 & 0.24 & 9 & 0.91 & 0.04 & SKKS \\
\hline BLO* & 39.17 & -86.52 & 50.51 & 23.35 & 0.96 & 0.32 & 25 & 0.34 & 0.01 & SKS \\
\hline CCM & 38.06 & -91.24 & 52.86 & 32.62 & 1.14 & 0.49 & 14 & 0.28 & 0.02 & PKS \\
\hline CCM & 38.06 & -91.24 & 38.57 & 28.3 & 0.92 & 0.23 & 18 & 0.38 & 0.02 & SKKS \\
\hline CCM & 38.06 & -91.24 & 37.46 & 29.85 & 0.82 & 0.38 & 53 & 0.28 & 0.01 & SKS \\
\hline $\mathrm{FA} 07^{*}$ & 34.73 & -86.71 & 54.1 & 7.78 & 0.94 & 0.04 & 2 & 1.9 & 0.06 & PKS \\
\hline FA07* & 34.73 & -86.71 & 29 & 4 & 0.45 & 0.6 & 1 & 10 & 0.22 & SKKS \\
\hline FA07* & 34.73 & -86.71 & 175 & 12 & 0.95 & 0.4 & 1 & 6 & 0.2 & SKS \\
\hline FA08* & 37.32 & -89.53 & 51 & 14 & 1.45 & 0.25 & 1 & 3.5 & 0.24 & SKS \\
\hline FA09* & 39.49 & -91.79 & 149 & 6 & 1.05 & 0.3 & 1 & 3 & 0.15 & SKKS \\
\hline FVM & 37.98 & -90.43 & 53 & 7 & 0.8 & 0.2 & 1 & 7.5 & 0.15 & PKS \\
\hline FVM & 37.98 & -90.43 & 13 & 7 & 0.55 & 0.12 & 1 & 3.5 & 0.06 & SKKS \\
\hline FVM & 37.98 & -90.43 & 49.28 & 16.96 & 0.88 & 0.09 & 4 & 0.9 & 0.04 & SKS \\
\hline LRAL* & 33.03 & -87 & 70.52 & 2.05 & 1.31 & 0.15 & 13 & 0.48 & 0.02 & PKS \\
\hline LRAL* & 33.03 & -87 & 61.77 & 3.8 & 1.74 & 0.32 & 8 & 0.78 & 0.05 & SKKS \\
\hline LRAL* & 33.03 & -87 & 63.22 & 7.16 & 1.25 & 0.31 & 14 & 0.91 & 0.04 & SKS \\
\hline MIAR & 34.55 & -93.58 & 95.43 & 8.36 & 0.83 & 0.14 & 6 & 1.15 & 0.03 & PKS \\
\hline MIAR & 34.55 & -93.58 & 59 & 22 & 1.4 & 0.5 & 1 & 3.5 & 0.24 & SKKS \\
\hline MIAR & 34.55 & -93.58 & 101.72 & 8.58 & 1 & 0.27 & 7 & 0.81 & 0.04 & SKS \\
\hline MM14 & 39.55 & -86.39 & 35 & 8 & 1.2 & 0.4 & 1 & 4 & 0.2 & SKKS \\
\hline MM14 & 39.55 & -86.39 & 48.56 & 2.83 & 0.86 & 0.18 & 2 & 1.56 & 0.03 & SKS \\
\hline MM16 & 38.92 & -88.3 & 99.36 & 18.38 & 0.63 & 0.04 & 2 & 3.34 & 0.08 & SKKS \\
\hline MM16 & 38.92 & -88.3 & 72 & 8 & 0.8 & 0.1 & 1 & 3 & 0.05 & SKS \\
\hline MM17 & 38.67 & -89.33 & 58 & 16 & 1.25 & 0.43 & 1 & 8 & 0.22 & PKS \\
\hline MM17 & 38.67 & -89.33 & 110 & 20 & 0.6 & 0.48 & 1 & 9 & 0.16 & SKS \\
\hline MM18 & 38.53 & -90.57 & 57 & 22 & 0.95 & 2.62 & 1 & 2.5 & 0.05 & SKS \\
\hline $\mathrm{MPH}^{*}$ & 35.12 & -89.93 & 57.1 & 7.21 & 1.2 & 0.19 & 4 & 0.78 & 0.03 & PKS \\
\hline MPH* & 35.12 & -89.93 & 91 & 22 & 1.05 & 2.6 & 1 & 4 & 0.14 & SKKS \\
\hline $\mathrm{MPH}^{*}$ & 35.12 & -89.93 & 79.05 & 39.39 & 1.33 & 0.42 & 5 & 0.5 & 0.04 & SKS \\
\hline OLIL* & 38.73 & -88.1 & 53.83 & 3.07 & 0.87 & 0.13 & 5 & 1.12 & 0.05 & PKS \\
\hline OLIL* & 38.73 & -88.1 & 51.88 & 5.66 & 0.94 & 0.04 & 2 & 2.4 & 0.04 & SKS \\
\hline OXF & 34.51 & -89.41 & 64.48 & 1.8 & 1.27 & 0.11 & 4 & 0.54 & 0.02 & PKS \\
\hline OXF & 34.51 & -89.41 & 61.78 & 3.43 & 1.1 & 0.16 & 3 & 1.95 & 0.08 & SKKS \\
\hline OXF & 34.51 & -89.41 & 61.83 & 4.64 & 1.19 & 0.14 & 4 & 0.63 & 0.03 & SKS \\
\hline PLAL & 34.98 & -88.08 & 62.41 & 2.11 & 1.21 & 0.11 & 3 & 0.86 & 0.04 & PKS \\
\hline PLAL & 34.98 & -88.08 & 50 & 2 & 1.8 & 0.32 & 1 & 1.5 & 0.17 & SKKS \\
\hline PLAL & 34.98 & -88.08 & 132.6 & 55.86 & 0.89 & 0.29 & 13 & 0.38 & 0.02 & SKS \\
\hline PVMO* & 36.41 & -89.7 & 62.61 & 5.65 & 0.87 & 0.1 & 3 & 1.58 & 0.05 & SKS \\
\hline SIUC* & 37.71 & -89.22 & 72.99 & 13.72 & 0.81 & 0.43 & 3 & 1.61 & 0.04 & PKS \\
\hline SIUC* & 37.71 & -89.22 & 110 & 18.1 & 0.55 & 0.09 & 5 & 2.24 & 0.02 & SKKS \\
\hline SIUC* & 37.71 & -89.22 & 88.62 & 16.77 & 0.7 & 0.13 & 21 & 0.81 & 0.01 & SKS \\
\hline SLM* & 38.64 & -90.24 & 49.25 & 14.73 & 0.84 & 0.11 & 6 & 0.82 & 0.03 & PKS \\
\hline SLM* & 38.64 & -90.24 & 56.45 & 7 & 1.19 & 0.42 & 9 & 0.37 & 0.04 & SKKS \\
\hline SLM $^{*}$ & 38.64 & -90.24 & 40.59 & 9.67 & 0.91 & 0.16 & 11 & 0.66 & 0.03 & SKS \\
\hline UALR* & 34.78 & -92.34 & 42.38 & 12.97 & 1.18 & 0.12 & 3 & 2.45 & 0.08 & PKS \\
\hline UALR* & 34.78 & -92.34 & 60 & 6 & 1.15 & 0.25 & 1 & 3 & 0.12 & SKKS \\
\hline UALR* & 34.78 & -92.34 & 68.92 & 7.72 & 0.9 & 0.03 & 3 & 2.05 & 0.05 & SKS \\
\hline USIN* & 37.97 & -87.67 & 58.49 & 2.12 & 0.99 & 0.17 & 4 & 1.48 & 0.06 & PKS \\
\hline
\end{tabular}


Table 2. Continued from previous page.

\begin{tabular}{|c|c|c|c|c|c|c|c|c|c|c|}
\hline $\begin{array}{l}\text { Station } \\
\text { name }\end{array}$ & $\begin{array}{l}\text { Coor } \\
\text { Latitude } \\
\text { (Deg.) }\end{array}$ & $\begin{array}{l}\text { lates } \\
\text { Longitude } \\
\text { (Deg.) }\end{array}$ & $\begin{array}{c}\text { Fast } \\
\text { direction } \\
\text { (Deg.) }\end{array}$ & $\begin{array}{c}\text { Fast } \\
\text { direction } \\
\text { ( } \Delta \text { degree })\end{array}$ & $\begin{array}{c}\text { Splitting } \\
\text { time } \\
\text { (s) }\end{array}$ & $\begin{array}{l}\text { Splitting } \\
\text { time } \\
(\Delta s)\end{array}$ & $\begin{array}{l}\text { Number } \\
\text { of events }\end{array}$ & $\begin{array}{r}\text { We } \\
\Delta \phi\end{array}$ & $\Delta s$ & Phase \\
\hline USIN* & 37.97 & -87.67 & 53.55 & 2.83 & 1.05 & 0.07 & 2 & 1.86 & 0.07 & SKKS \\
\hline USIN* & 37.97 & -87.67 & 57.68 & 5.35 & 0.95 & 0.2 & 6 & 0.78 & 0.03 & SKS \\
\hline UTMT* & 36.34 & -88.87 & 64 & 8 & 0.9 & 0.23 & 1 & 4 & 0.12 & PKS \\
\hline UTMT* & 36.34 & -88.87 & 120 & 7 & 0.35 & 0.2 & 1 & 11 & 0.31 & SKKS \\
\hline UTMT* & 36.34 & -88.87 & 54.6 & 66.19 & 0.95 & 0.5 & 3 & 0.96 & 0.06 & SKS \\
\hline WCI* & 38.23 & -86.29 & 53.62 & 1.64 & 0.92 & 0.19 & 3 & 1.23 & 0.04 & PKS \\
\hline WCI* & 38.23 & -86.29 & 32.38 & 7.78 & 1 & 0 & 2 & 3.33 & 0.08 & SKKS \\
\hline WCI* & 38.23 & -86.29 & 119.21 & 61.11 & 0.82 & 0.25 & 14 & 0.67 & 0.02 & SKS \\
\hline WVT* & 36.13 & -87.83 & 56 & 6 & 0.65 & 0.12 & 1 & 3 & 0.06 & PKS \\
\hline WVT* & 36.13 & -87.83 & 79 & 1 & 0.8 & 0.2 & 1 & 3.5 & 0.15 & SKKS \\
\hline WVT* & 36.13 & -87.83 & 49.71 & 10.14 & 0.95 & 0.55 & 6 & 0.8 & 0.07 & SKS \\
\hline
\end{tabular}

*Stations have not been analyzed for shear wave splitting before.

tion of the fast direction is consistent with the North American APM. There is a significant change in the fast directions between the two stations suggesting that UALR is situated on the edge of the craton and hence the splitting pattern at these stations resembles that of cratonic stations.

Station CCM, FVM, SLM, MM18, MM17, MM16, SIUC and OLIL are located on Mazatzal belt (1.61-1.68 Ga) which is made up of several blocks with varying ages. ${ }^{21}$ The age differences of the Mazatzal belt are likely to cause spatial variations of the splitting parameters as shown in Table 2 while station MM14, BLO, WCI, FA08 and USIN are on the granite rhyolite terrain (1.38-1.48 Ga). These terrains belongs the North American craton. Splitting patterns from these stations are complex under the assumption of simple asthenospheric flow. Our splitting measurements for cratonic stations are explained well by the double layer parameters shown in Table 1. The lower layer has fast directions at approximately $\mathrm{N} 70^{\circ} \mathrm{E}$ while the top layer is at approximately $\mathrm{N} 22^{\circ} \mathrm{E}$. The lower layer is consistent with the direction of the APM while anisotropy on the upper layer is most like due lithospheric contribution. This double layer anisotropy is consistent with the result of a recent joint inversion of surface waveforms and shear wave splitting measurements, which revealed a two-layer anisotropy model $^{15}$ for stable North America. Stations within the New Madrid seismic zone show double anisotropy model with the parameters shown in Table 1.

\section{Depth extent of faults}

Seismic studies by Liu et $a l .{ }^{30}$ at Reelfoot lake reveals a westerly dipping basin bounded by Reelfoot reverse fault zone, the Ridgely right-lateral transpressive fault zone on the east, and the Cottonwood Grove right-lateral strike-slip fault in the middle of the basin. The depth extent of these major faults system in the NMSZ is unknown but high-resolution seismic reflection surveys ${ }^{48,49}$ have been used to study subsurface faulting. The results revealed that the faults systems from seismic reflection profiles are confined to the upper crust. The Ridgely fault zone consists of two northeast-striking faults within the Mississippi embayment and has $15 \mathrm{~m}$ of postEocene, up-to-the-east displacement and appears to locally control the eastern limit of Mississippi River migration. Our observed splitting parameters have a nearly parallel trend with this faults system. The Cottonwood Grove fault zone passes through the center of the NMSZ close to station MPH and PVMO and has approximately $5 \mathrm{~m}$ of up-to-the-east displacement. Work by Chiu et al. ${ }^{50}$ suggests that a $31^{\circ}$ to $48^{\circ}$, southwest-dipping reverse fault lies beneath the Lake County uplift at hypocentral depths of 4 to $13 \mathrm{~km}$. Our data set allows a more spatially comprehensive study of splitting in NMSZ, and we find some evidence for splitting parallel to maximum compressive stress in stations that far from the rift but not enough to conclude that either parallel dikes or magma-filled lenses are the dominant causative mechanism of anisotropy.

\section{Simple asthenospheric flow}

Lattice preferred orientations of the fast olivine fast axis develop in the asthenosphere because of dislocation-creep deformation associated with simple shear at the base of the plate. ${ }^{7,8}$ These orientations are roughly horizontal and in the direction of shear. Simple asthenospheric flow due to the passive shearing of the asthenosphere by the moving plate has been invoked to interpret splitting fast axis direction parallel to APM. ${ }^{2,33}$ Our fast directions show spatial and azimuthal variation through- out the study area (Figure 1) and are therefore not explained by the simple asthenospheric flow hypothesis. The polarization for cratonic stations are consistent with the asthenospheric flow hypothesis if the plate is moving with respect to the underlying mantle, creating simple shear at the base of the craton. If there is relative motion between the lithosphere and the underlying mantle, the asthenosphere must flow around and/or beneath craton keels. Fouch et al. ${ }^{12}$ interpreted splitting parameters in North America as due to asthenospheric flow associated with basal lithospheric topography. In most regions of gentle topographical gradients, the fast axis is parallel to APM. ${ }^{31}$ In regions where the topographic gradients are large, fast axis direction tends to be parallel to the topographic contours of the Moho topography, which are assumed to reflect the same variations in basal lithospheric topography. Stations CCM and stations from MOMA array were previously studied by Fouch et al. ${ }^{12}$ suggest that the fast direction are approximately parallel to the craton edge can be explained by edge flow around the keel and/or rift-parallel flow. Their calculations predict that splitting beneath flat lithospheric keel would have $\Phi$ parallel to APM, whereas splitting elsewhere would have $\Phi$ parallel to the depth contours at the base of the lithosphere because the rigid lithosphere is moving through the asthenosphere.

\section{Vertical asthenospheric flow}

A study by Forte et al. ${ }^{14}$ based on tabular slab geometry descending into the mantle below the Central Mississippi River Valley has shown dramatic change in mantle flow direction associated with subducting Farallon slab. For vertical asthenospheric flow, the expected splitting times would be small. However, the observed splitting measurements are more than the 
global average and hence cannot be explained by vertical asthenospheric flow. In cases where measured $\delta$ t are longer than expected for lithospheric anisotropy, the relative motion between a separately moving plate and asthenosphere can be invoked as contributing to the measured anisotropy. Our station averaged fast polarization directions show some degree of variation throughout the study area (Figures 1 and 5) and are therefore not explained by the vertical flow hypothesis.

\section{Conclusions}

SKS splitting observations in the NMSZ and the surrounding area suggest a complex pattern of anisotropy across the region. A single layer of anisotropy is inferred beneath some of the stations while other stations show evidence of the asthenosphere as the source of the anisotropy. Since the observed fast directions are sub-parallel to the Reelfoot fault system, it is likely that asthenospheric flow is responsible for the observed anisotropy. Platemantle interaction is dominated by the Eastern North America due to the higher level of shear stress and the larger spatial extent. Thus the mantle under NMSZ may move in a different direction without affecting the motion of North America. On the other hand, the motion of deep lithospheric roots is probably to some degree correlated with the motion of the mantle below. Shear wave splitting measurements suggest that the anisotropy observed at the NMSZ is complex. The complexity can be explained by combination of different sources. The two-layer model proves to be the ideal model to explain the measured splitting parameters on the New Madrid seismic zone.

\section{References}

1. Savage MK. Seismic anisotropy and mantle deformation: what have we learned from shear wave splitting?. Rev Geophys 1999;37:65-106.

2. Silver PG, Chan WW. Shear-wave splitting and continental mantle deformation. J Geophys Res 1991;96:16429-54.

3. Gao S, Davis PM, Liu H, et al. Asymmetric upwarp of the Asthenosphere beneath the Baikal Rift zone, Siberia. J Geophys Res 1994;99:15319-30.

4. Silver PG. Seismic anisotropy beneath the continents: probing the depths of geology. Ann Rev Earth Planet Sci 1996;24:385-432.

5. Mainprice D, Tommasl A, Couvy H, et al. Pressure sensitivity of olivine slip systems and seismic anisotropy of Earth's upper mantle. Nature 2005;433:731-3.
6. Karato S. Seismic anisotropy due to lattice preferred orientation of minerals: kinematic or dynamic? Am Geophy Union 1987;39:455-71.

7. Zhang SQ, Karato SI. Lattice preferred orientation of olivine aggregates deformed in simple shear. Nature 1995;375:774-7.

8. Nicolas A, Christensen NI. Formation of anisotropy in upper mantle peridotites-a review. In: K. Fuchs, C. Froidevaux, eds. Composition, structure and dynamics of the lithophere- asthenosphere system. vol. 16. Washington, DC: Geodyn Ser AGU; 1987. pp 111-123.

9. Mainprice D, Barruol G, Ben Ismaïl W. The seismic anisotropy of the Earth'smantle: from single crystal to polycrystal. In: S.-I. Karato, A.M. Forte, R.C. Liebermann, G. Masters, L. Stixrude, eds. Earth's deep interior: mineral physics and seismic tomography: from atomic to global. Washington, DC: AGU Geophysics Monograph; 2000. pp 237-264.

10. Babuska V, Cara M. Seismic anisotropy in the earth. Dordrecht: Kluwer Academic Publishers; 1991.

11. Kaminski E, Ribe NM. Timescales for the evolution of seismic anisotropy in mantle flow, Geophys 2002;3:1051.

12. Fouch MJ, Fischer KM, Parmentier EM, et al. Shear wave splitting, continental keels, and patterns of mantle flow. J Geophys. Res 2000;105:6255-75.

13. Gao S, Davis PM, Slack PD, et al. SKS splitting beneath continental rift zones. J Geophys Res 1997;102:22781-95.

14. Forte AM, Mitrovica JX, Moucha R, et al. Descent of the ancient Farallon slab drives localized mantle flow below the New Madrid seismic zone. Geophys Res Let 2007;34: L04308.

15. Marone M, Romanowicz B. The depth distribution of azimuthal anisotropy in the continental upper mantle. Nature 2007;447:198-201.

16. Rowlands HJ, Booth DC, Chiu JM. Shearwave splitting from microearthquakes in the New Madrid seismic zone. Can J Expl Geophys 1993;29:352-62.

17. Crampin S. The fracture criticality of crustal rocks. Geophys J Int 1994;118:42838 .

18. Barruol G, Mainprice D. A quantitative evaluation of the contribution of crustal rocks to the shear wave splitting of teleseismic SKS waves. Phys Earth planet Inter. 1993;78:281-300.

19. Gao S, Liu KH, Stern RJ, et al. Characteristics of mantle fabrics beneath the south-central United States: Constraints from shear-wave splitting measurements. Geosphere 2008;4:411-7.

20. Barruol G, Silver PG, Vauchez A. Seismic anisotropy in the eastern US: deep struc- ture of a complex continental plate. J Geophys Res1997;102:8329-48.

21. Holm DK, Anderson R, Boerboomc TJ, et al. Reinterpretation of Paleoproterozoic accretionary boundaries of the north-central United States based on a new aeromagnetic-geologic Precambrian Res 2007;157:71-9.

22. Eisele $\mathrm{J}$, Isachsen $\mathrm{C}$. Crustal growth in southern Arizona: U-Pb geochronologic and sm-nd isotopic evidence for Addition of the paleoproterozoic cochise block to the Mazatzal province. Am. J Sci 2001;301:773-97.

23. Karlstrom KE, Bowring SA. Early proterozoic assembly of tectono-stratigraphic terranes in southwestern North America. J Geol 1988;96:561-76.

24. Ervin CP, McGinnis LD. Reelfoot rift-reactivated precursor to the Mississippi embayment. Geol Soc Am Bull 1975;86: 1287-95.

25. Braile LW, Keller GR, Hinze WJ, Lidiak EG. An ancient rift complex and its relation to contemporary seismicity in the New Madrid seismic zone. Tectonics 1982;1: 225-37.

26. Cox RT, Van Arsdale RB. Hotspot origin of the Mississippi embayment and its possible impact on contemporary seismicity. Eng Geol 1997;46:5-12.

27. Kolata DR, Nelson WJ. Role of the Reelfoot Rift-Rough Greek Graben in the evolution of the Illinois Basin. In: R.W. Ojakangas, A.B. Dickas, J.C. Green, eds. Middle Proterozoic to Cambrian rifting, central North America. Boulder, C0: The Geological Society of America; 1997. Special Paper 312, pp 287-298.

28. Fischer K, Rondenay S, Syracuse E, et al. Investigating crust and mantle structure with the Florida-to-Edmonton Broadband Array, surface of the Earth: North America, 2006; Iris 5-Year Proposal. NOT CLEAR BO0K? JOURNAL?

29. Silver PG, Savage MK. The interpretation of shear wave splitting parameters in the presence of two anisotropic layers. Geophys J Int 1994;119:949-63.

30. Liu KH, Gao SS, Gao Y, Wu J. Shear wave splitting and mantle flow associated with the deflected Pacific slab beneath northeast Asia. J. Geophysical Res 2008;113: 1978-2012.

31. Gripp AE, Gordon RG. Young tracks of hotspots and current plate velocities. Geophys J Int 2002;150:321-61.

32. Savage MK, Silver PG. Mantle deformation and tectonics: constraints from seismic anisotropy in the western United States. Phys Earth Planet Int 1993;78:207-27.

33. Vinnik LP, Makeyeva L, Milev A, Usenko A. Global patterns of azimuthal anisotropy and deformation in the continental man- 
tle. Geophys J Int 1992;111:433-47.

34. Mainprice D, Silver PG. Interpretation of SKS-waves using samples from the subcontinental lithosphere. Phys Earth Planet Inter 1993;78:257-280.

35. Christensen NI. The magnitude, symmetry, and origin of upper mantle anisotropy based on fabric analysis of ultramafic tectonites. Geophys J R Astron Soc 1984;76:89-111.

36. Gao S, Davis PM, Slack PD, et al. SKS splitting beneath continental rift zones. J Geophys Res 1997;102:22781-95.

37. Gledhill K, Stuart G. Seismic anisotropy in the fore-arc region of the Hikurangi subduction zone, New Zealand. Phys Earth Planet Int 1996;95:211-25.

38. Barruol G, Ismail WB. Upper mantle anisotropy beneath the African IRIS and Geoscope stations. Geophys J Int 2001;146:549-61.

39. Crampin S, Peacock S. A review of shearwave splitting in the compliant crack-critical anisotropic Earth. Wave Motion 2005;41:59-77.

40. Zoback MD, Zoback M. State of stress in the conterminous United States. J Geophys Res 1980;85:6113-56.

41. Silver PG, Chan WW. Shear-wave splitting and continental mantle deformation. J Geophys Res 1991;96:16429-54.

42. Plomerova J, Vecsey L, Babuska V, LAPNET Working Group. Domains of Archean mantle lithosphere deciphered by seismic anisotropy - inferences from the LAPNET array in northern Fennoscandia. Solid Earth 2011;2:303-13.

43. Montagner JP. Where can seismic anisotropy be detected in the earth's mantle? Pure Appl Geophys 1988;151:223-56.

44. Assumpcao M, Guarido M, van der Lee S, Dourado JC. Upper-mantle seismic anisotropy from SKS splitting in South American stable platform: a test of asthenospheric flow models beneath the lithosphere. Lithosphere 2011;3:173-80.

45. Barruol G, Deschamps A, D'everchere J, et al. Upper mantle flow beneath and around the Hangay dome, central Mongolia. Earth Planet Sci Lett 2008;274:221-33.

46. Wustefeld A, Bokelmann G, Barruol G. Evidence for ancient lithospheric deforma- tion in the East European Craton based on mantle seismic anisotropy and crustal magnetics. Tectonophysics 2010;481:1628.

47. Mareschal JC, Jaupert C. Archean thermal regime and stabilization of cratons. In: K. Benn, J.-C. Mareschal, K.C. Condie, eds. Archean geodynamics and environments. Washington, DC: AGU Geophysical Monograph 164; 2006. pp 61-73.

48. Bexfield CE, McBride JH, Pugin AJ, et al. Integration of $\mathrm{P}$ - and $\mathrm{SH}$-wave high-resolution seismic reflection and micro-gravity techniques to improve interpretation of shallow subsurface structure: New Madrid seismic zone. Tectonophysics 2006;420:521.

49. McBride JH, Stephenson WJ. Contributions to neotectonics and seismic hazard from shallow geophysical imaging. Special Tectonophysics 2003;368:1-227.

50. Chiu JM, Johnston AC, Yang YT. Imaging the active faults of the central New Madrid seismic zone using PANDA array data. Seismol Res Lett 1992;63:375-93. 